\title{
Priorities and Pitfalls Of Music Education: An Open Letter
}

When music is not taught in schools, the reason is simply that it is not valued highly enough, says this writer, who asks: Do we want to limit access to musical knowledge to an elite, or do we want to make it available to all citizens to appreciate and enjoy?

\section{By Paul R. Lehman}

W HY DOES YOUR school need a strong music program? Why is music important in the curriculum? Who needs music, anyway?

Through the years, these questions have been answered by most of the great philosophers and educators of western civilization. One might think that collectively this enormous array of intellectual talent would be able to lay to rest once and for all any lingering doubts that music is essential in education. But somehow the question continues to be asked. Why?

\section{Many Constituencies, Many Views}

One reason is that, even though answers are abundant, there are so many different public constituencies, with so many different views as to the purposes

PAUL R. LEHMAN is professor and associate dean, School of Music, the University of Michigan, Ann Arbor. of education, that it is not easy to provide a simple rationale that every individual will accept as conclusive. Also, there is sometimes a mismatch between the claims of music teachers and the perceptions of the public, or even of principals, as to what actually happens in the music classroom.

But fundamentally the problem has to do not with the absolute importance of music but with its relative importance. I don't think there is much disagreement that good music, well taught, is important in education. The difficulty arises when there doesn't appear to be enough time or resources to teach everything worthwhile and choices must be made.

The question isn't, "Is music important?" The question is, "How important

This article is based on Paul Lehman, Music in Today's Schools: Rationale and Commentary (Reston, Va.: Music Educators National Conference, 1987). 
is music relative to all the other demands being made on the schools?"

The consensus of those who have considered the issues of curriculum most carefully is that music is one of the basics. The consensus is that music and the other arts are extremely important in education, and that they should have a high priority.

\section{Research Supports the Arts}

Consider the major contributions to the great debate on educational reform of the past four years. Those reports that are most thorough and thoughtful, those that are best documented, and those that are based on the most extensive field work also tend to be most strongly supportive of the arts.

Ernest Boyer, for example, says in High School that the arts "are the means by which a civilization can be measured .... [They] are an essential part of the human experience. They are not a frill. We recommend that all students study the arts .... These skills are no longer just desirable. They are essential if we are to survive together with civility and joy. ${ }^{1}$

In The Paideia Proposal, Mortimer Adler writes, "[There] are three areas of subject matter indispensable to basic schooling-language, literature, and the fine arts; mathematics and natural sciences; history, geography, and social studies. Why these three? They comprise the most fundamental branches of learning. No one can claim to be educated who is not reasonably well acquainted with all three."2

The College Board, in its landmark publication Academic Preparation for College, takes the firm position that all students should study the arts whatever their major fields of study are to be, and that each student should undertake more

1. Ernest Boyer, High School (New York: Harper and Row, 1983), pp. 97-98.

2. Mortimer Adler, The Paideia Proposal (New York: Macmillan, 1982), pp. 22-24. intensive preparation in at least one field of the arts. ${ }^{3}$

\section{Is There Time for Music?}

Given this massive reservoir of unequivocal and enthusiastic support, why is it that some schools still fail to provide a strong program in music? One of the excuses we sometimes hear is that there is not enough time in the school day.

John Goodlad, whose book $A$ Place Called School, ${ }^{4}$ is based on detailed observations of more than 1,000 classrooms at every level, finds this argument to be totally unsupportable. Goodlad's staff gathered data from more than 27,000 teachers, parents, and students during a period of nearly three years. His study is one of the most thorough in the history of education. One of his conclusions is that schools should become more self-conscious concerning the efficient use of students' time.

He claims that all schools could gain at least two hours of additional instructional time per week merely by observing more carefully the beginning and ending times of school days, lunch breaks, and class periods. He also states that virtually every teacher could gain another 10 percent by accomplishing more quickly and efficiently noninstructional activities that are often done casually or inefficiently.

At the secondary level, Goodlad believes, up to 18 percent of each student's program should be devoted to literature and languages, up to 18 percent to mathematics and science, up to 15 percent each to social studies, vocational studies, and the arts, and up to 10 percent to physical education. ${ }^{5}$

3. Academic Preparation for College (New York: The College Board, 1983), pp. 16-18. 4. John Goodlad, A Place Called School (New York: McGraw-Hill, 1983), pp. 12728.

5. Ibid., pp. 286-87. 
This is the program for every student. And it includes 15 percent in the arts. The other 10 percent should be available to pursue the special interests and abilities of the individual student, which, of course, may include the arts.

Another excuse we often hear for not having a strong music program is that budget problems have required a reduction in the teaching staff. This is largely a misrepresentation. Expenditures for teachers' salaries are determined by the overall size of the staff, not by what the teachers are teaching. A school that claims to be cutting its music program to save money is in fact merely decreasing its teacher-pupil ratio to save money. The students have to be assigned somewhere. There can be no saving unless other classes are increased in size. This would be true no matter what was cut.

A school that dismisses or refuses to hire music teachers in order to hire more teachers in other fields has probably lost sight of the true purposes of education: the pursuit of truth and beauty, the development of human capacities, and the improvement of the quality of life. It is trying to achieve short-term goals by neglecting long-term goals. It is concentrating on the superficial aspects of life that bring instant gratification while overlooking the sources of universal human fulfillment that make life worth living.

\section{A Question of Priorities}

The unvarnished truth is that when music is not taught the reason is simply that it is not valued highly enough. This often means merely that the principals themselves did not experience challenging, rewarding, high-quality music programs in school. As a result, tragically, the next generation is destined to be equally deprived of some of the greatest satisfaction life has to offer.

The time is available. Money is not the real problem. The question is simply one of priorities.
It's easy to lose sight of the fundamental importance of music in education because we're distracted by its pervasive role in entertainment, by its commercial uses, and by its ability to serve all manner of diverse purposes. But the meaning and the unique usefulness of music do not lie in its ability to entertain us, to convey commercial messages, or to serve other nonmusical purposes, even though these functions may seem dominant in today's world of electronic telecommunications. The meaning and the usefulness of music lie much deeper in the human psyche.

\section{A school that dismisses or refuses to hire music teachers in order to hire more teachers in other fields has probably lost sight of the true purposes of education}

It has often been observed that a nation is judged by posterity not by the size of its gross national product, nor by the destructive capability of its military arsenal, but by its contributions to the arts and humanities. This has been true throughout history. It has become even more true as we expand our potential for making our planet uninhabitable. It is the achievements of every civilization in the arts and humanities that remain when everything else is swept away by time.

Let me call your attention to a very serious but often unrecognized threat to programs in music and the arts that has arisen as a direct result of the educational reform movement. Increasing the course requirements in both the middle school and the high school without increasing the number of periods in the school day invariably makes it more difficult for students to schedule classes in the arts. 
Some schools still cling to a six-period day. Experience suggests that it's almost impossible to maintain an adequate arts program in a six-period day. Schools with nine-period days tend to have far fewer problems in scheduling the arts.

Why should the day have only six periods? After all, should the curriculum be designed to fit the schedule, or should the schedule be designed to fit the curriculum?

Another important caveat concerning time should be raised. An increasing number of school performing groups are spending an excessive amount of time performing for athletic contests or participating in competitions and parades. Frequently, this amounts to blatant exploitation of the students for the entertainment of the public or for the ego gratification of the community or, occasionally, of the director. In any case, these excesses have no place in an educational program.

A reasonable amount of public performance provides a necessary and proper laboratory for the demonstration of musical learning, but performing groups in schools exist for educational purposes. They are credit-bearing classes. They have no business spending an excessive amount of time participating in public spectacles with little redeeming educational value. We owe it to our students to keep these activities within proper limits and to be certain that our major emphasis is on learning music. 6

The Music Educators National Conference believes that a balanced curriculum in the secondary school includes bands, orchestras, and choral groups as well as elective classes. At least one

6. For specific recommendations see Guidelines for Performances of School Music Groups: Expectations and Limitations (Reston, Va.: Music Educators National Conference, 1986). course in music should be available to every student, including those who lack the interest, ability, or time to participate in the select performing groups.

The school day should include at least seven or eight periods. At every level music should be taught by qualified teachers in adequate facilities with sufficient materials and equipment. ${ }^{7}$

\section{Ensuring a Quality Curriculum}

Even though our nation has been preoccupied with educational reform recently, there has been very little discussion of the criteria by which quality can be recognized in schools. This is partially because it's so difficult to relate quality to quantitative standards. Quality is ultimately determined by what actually takes place between teachers and students. But even though many of the obvious criteria tend to be either superficial or unreliable, there are some valid indicators that one can look for in judging quality. I believe that one of the most important and useful of these indicators is the richness of the curriculum.

All schools provide pretty much the same offerings in languages and literature, math, science, and social studies. But they differ greatly in their offerings in the arts. We all know schools that provide extensive arts programs. Very often, these are schools that we recognize as being among the best. No one can say whether good arts programs are a cause of high quality in schools, or whether they're simply one result of high quality. But there is a strong and positive correlation between a high degree of excellence in a school and a vigorous, dynamic program in the arts. The breadth and depth of the curriculum in the arts seems certainly to be one

7. The School Music Program: Description and Standards, 2nd ed. (Reston, Va.: Music Educators National Conference, 1986). 
valid index of quality in a school system.

Why does your school need a strong music program? Because music is intrinsically worthwhile. It is a unique field of study with its own special body of knowledge, skills, and ways of thinking. It has tremendous appeal to human beings. It is worth knowing. It is important and valuable in itself. It needs no further justification. Every member of society should have the ability to perform, to create, and to listen to music with understanding.

But even though no further justification should be necessary, we know that it sometimes is. Fortunately, there are other rationales available. Some are complex. Some overlap. Some are more effective with certain segments of the public than with other segments. Each may be used where and when it can be helpful. The emphasis will depend upon the interests and concerns of the community.

These rationales include the following:

1. The arts are an important part of damental purpose of education has been to transmit our cultural heritage to succeeding generations. Music is one of the most powerful, the most compelling, and the most glorious manifestations of our heritage.

Most parents want their children to be familiar with the contributions to civilization of Shakespeare, Michelangelo, and Beethoven, as well as the contributions of Galileo, Newton, and Einstein. A student who is allowed to leave school without the formal study of music has been cheated just as surely as though he or she had been denied the opportunity to study literature, history, or science.

2 Another of the important functions 2. of schools is to help studerts to develop their potential. Musical potential is one of the basic abilities that exist in every human. Howard Gardner, in his book Frames of Mind, has offered persuasive evidence for the existence of seven relatively autonomous intellectual competencies which he refers to as human intelligences. These include, in the order he presents them, linguistic intelligence, musical intelligence, logical-mathematical intelligence, spatial intelligence, bodily-kinesthetic intelligence, and two forms of what he calls personal intelligence.

Despite the relationship between musical learning and other forms of learning, Gardner concludes that "the core operations of music do not bear intimate connections to the core operations in other areas; and therefore, music deserves to be considered as an autonomous intellectual realm."8

Although everyone has musical ability, some people never have a chance to develop it. Schools should provide all citizens with the opportunity to test the limits of their potential in as many domains of human endeavor as possible. Otherwise they will never know in what fields they could have achieved, and they will never know how far they could have gone.

3 Music provides a much-needed out. let for creativity and self-expression. It enables us to express our noblest thoughts and feelings. It engages our imaginations. It allows us to assess our uniqueness. These are particularly important functions in a world increasingly dominated by electronic technology.

Music provides means for self-realization and self-fulfilling productivity. By participating in music we contribute to our individual growth. By participating in music we help to ensure that our lives are satisfying, purposeful, and worthwhile. By participating in music

8. Howard Gardner, Frames of Mind: The Theory of Multiple Intelligences (New York: Basic Books, 1983), p. 126. 
we make our own personal contribution to the quality of life.

4. Music in the school provides an students who have difficulty with other aspects of the curriculum. It is essential that every student succeed in something. The curriculum should not consist solely of activities so similar to one another in their intellectual demands that those individuals whose abilities lie elsewhere are destined to fail in everything they do.

For some students music can make school tolerable. Most music teachers have known students who came to school only because of the joy and satisfaction they received from participating in music. Some students find no other refuge in school. Only in music are their talents appreciated, their contributions respected, and their achievements valued. Music has proved itself repeatedly to be a superb means of preventing dropouts.

5 The study of music can help the $\mathcal{~ - ~ s t u d e n t ~ t o ~ u n d e r s t a n d ~ b e t t e r ~ t h e ~}$ nature of humankind. It reveals unique aspects of our relationship with other human beings and with our environment. ${ }^{9}$ It provides a readily accessible avenue to the study of other cultures.

If we wish to learn more about ourselves and others we must discover what we like and why we like it. Why does music have such enormous power to bring pleasure to people? What kinds of music are most pleasurable? Why? In these matters education changes the object perceived. The task of the music teacher is to show the student what beauties exist in music when the obstacles to perception-such as prejudice,

9. See Foster McMurray, "Pragmatism in Music Education," in Basic Concepts in Music Education, Fifty-Seventh Yearbook of the National Society for the Study of Education, Part I (Chicago, Ill.: University of Chicago Press, 1958), pp. 30-61. unfamiliarity, and ignorance-are removed.

6 The study of music can increase the

- satisfaction that the student is able to derive from music and enable him or her to deal with more sophisticated and complex music. Formal study of music can sharpen one's perception, raise one's level of appreciation, and expand one's musical horizons. All this will increase the degree of pleasure one can derive from making or listening to music.

We are sometimes told that students should study music because they are constantly surrounded by it. This is just as much a reason for not studying music as for studying it. If a person is content to wallow indiscriminately in the trivial banality of the popular culture, there's no need for formal study at all. But anyone who glimpses the magic that lies beneath the surface in the world of music can no longer be satisfied with shallowness and superficiality.

7 Music is one of the most powerful

- and profound symbol systems that exists. Just as everyone must study our verbal and mathematical symbol systems, so too should everyone study the symbol systems represented by music and art. The ability to create symbols and the obsession to use them is what makes mankind uniquely human, and for this reason should be cultivated and strengthened at every opportunity.

According to Suzanne Langer, symbol-making is mankind's most human activity. It is an activity more fundamentally human than earning a living. Thus, music is by no means merely an adomment of life; it is a basic manifestation of being human. If we fail to cultivate our unique ability to make and use symbols, and allow it to atrophy over time, our humanity will be irreparably diminished. 10

10. Suzanne Langer, Philosophy in a New Key (New York: Mentor, 1948). 
8 One of the things that schools teach 8 . implicitly is that every important question has a right answer. Outside the school this is not true. The important questions facing society almost never have clear-cut answers. Life is filled with ambiguities. There are many aspects of our existence that cannot be quantified. Every student must learn to cope with the subjective and the ambiguous. Music teaches this very well. There are often several acceptable solutions to a musical problem or several acceptable interpretations of a musical work.

Music and the other arts are different from the other basic disciplines of the curriculum in that they do not reflect a preoccupation with right answers. There is no need to apologize for this difference; we should publicize it and take advantage of it. In this respect music and the arts are more like life itself than are the other disciplines.

Education urgently needs this balanced perspective. The fixation on right answers, so commonplace in education today, creates an artificial environment inconsistent with reality and leaves the student with a distorted view of the world.

O Finally, and perhaps most impor- tant, music exalts the human spirit. It enhances the quality of life. It transforms the human experience. It brings joy and pleasure to human beings in every society and in every culture. It brings solace to mankind in the ordinary activities of daily life, and it is an indispensable adjunct to our happiest and our most solemn occasions.

Music represents one of the most basic instincts in humans. This is why it has played a major role in the social and cultural fabric of every civilization ever known. And it will continue to do so as far into the future as anyone can see. The only question is whether we want to limit access to musical knowledge and skills to an elite or whether we want to make them available to all our citizens to appreciate and enjoy. The answer should be obvious.

Who needs music? Everyone does.

\section{Toys on Television}

U.S. and Canadian toy companies spend an average of $\$ 350$ million annually on television advertising. According to Maclean's magazine (Dec. 1986), "There are at least 20 shows on U.S. television that are financed and controlled directly by toy companies." 